Наносистели, нанолатеріали, нанотехнології Nanosistemi, Nanomateriali, Nanotehnologii 2017 , т. 15, № 4, сc. 611-618 (c) 2017 IMФ (Інститут металофізики ім. Г. В. Курдюмова НАН України) Надруковано в Україні. Фотокопіювання дозволено тільки відповідно до ліцензії

PACSnumbers: 47.61.Ne, 66.20.Ej, 78.67.Ve, 81.70.Cv, 82.70.Dd, 82.70.Kj, 83.80.Hj

\title{
Laser Optoacoustical Method for Investigation of Some Physical Properties of Oil and Petroleum
}

\author{
M. A. Musayev and I. I. Abbasov \\ The Azerbaijan State University of Oil and Industry, \\ Azadliq Ave., 20, \\ AZ1010 Baku, Azerbaijan
}

The laser generation of sound waves in strongly absorbing liquids is discussed. We demonstrate the experimental method to determine simultaneously both velocity of sound and light-absorption coefficient in liquids. With this method, measurements of these values for different oils are carried out, and the temperature coefficients of velocity of sound and gummosity are determined.

Обговорюється лазерне генерування звукових хвиль у сильно поглинальних рідинах. Ми демонструємо експериментальну методу для одночасного визначення швидкости звуку та коефіцієнта поглинання світла у рідинах. Цією методою проводяться міряння значень зазначених величин для різних олив (нафти), а також визначаються температурні коефіцієнти швидкости звуку та смолистість.

Обсуждается лазерная генерация звуковых волн в сильно поглощающих жидкостях. Мы демонстрируем экспериментальный метод для одновременного определения скорости звука и коэффициент поглощения света в жидкостях. Этим методом проводятся измерения значений указанных величин для разных масел (нефти), а также определяются температурные коэффициенты скорости звука и смолистость.

Key words: optoacoustical signal, absorption coefficient, acoustic wave, sound speed, gummosity.

Ключові слова: оптико-акустичний сигнал, коефіцієнт поглинання, акустична хвиля, швидкість звуку, смолистість.

Ключевые слова: оптико-акустический сигнал, коэффициент поглощения, акустическая волна, скорость звука, смолистость.

(Received 4 July, 2017) 


\section{INTRODUCTION}

For effective selection of machines and gears for a mining, hauls, processing and consumptions of oil, it is necessary to know its components and their parameters. The physicochemical properties of oil are extremely various; even within the limits of one reservoir, the characteristics of oil permanently vary.

Main physical properties of oils are sound velocity and lightabsorption coefficient. The experimental determination of sound velocity alongside with analysis of other parameters of medium allows calculating relevant characteristics of medium such as a compressibility and thermal capacity. The sound velocity also is connected to evaporation heat by surface tension and other parameters of medium $[1,2]$. The light-absorption coefficient is also parameter, which characterizes qualities of oil with adequate accuracy $[3,4]$.

The available conventional methods of measurement of a sound velocity are composite. These methods envision usages quartz converters, optics, a technique of photographic registration of a spectrum, etc. [5, 6]. For determination of absorbency, the photoelectric calorimeter operating will be used, which one is based on matching of two light beams passing through solution with oil and through a clean solvent. The comparison of the obtained data allows defining an absorption coefficient of light. As this method is also visible, it is enough composite and does not give possibility to determine directly required value.

The experimentally method of simultaneous determination of these two relevant parameters in oil and petroleum is offered and realized. Based on the obtained results, a temperature coefficient of a sound velocity and gummosity of oils are determined.

\section{THERMOOPTICAL SOUND GENERATION}

The essence of the given method is encompass bayed following. When strongly absorbing medium is irradiated with a short laser pulse $\left(\tau_{l}<\left(\alpha C_{0}\right)^{-1}, \tau_{l}\right.$-pulse duration of a laser radiation, $\alpha-$ absorption coefficient of laser radiation in medium, $C_{0}$-sound velocity), the heating of medium is possible to consider practically as instantaneous (Fig. 1). Then, the bulk density of a heat secured in medium is described by expression $\alpha \varepsilon_{s} \exp (-\alpha z)$ (where $\varepsilon_{s}$-density of energy incident on medium), and temperature variation of medium is described by expression as follows:

$$
T^{\prime}=\frac{\alpha \varepsilon_{s}}{\rho_{0} c_{p}} \exp (-\alpha z) .
$$



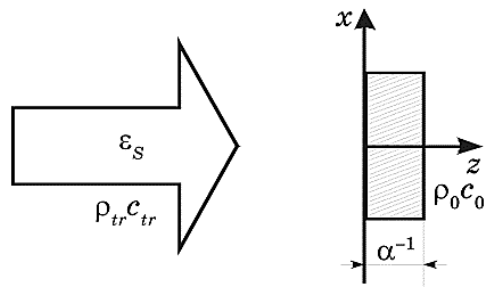

Fig. 1.

During influence a laser pulse density of medium has not time essentially will change, and at the expense of an inhomogeneous temperature field forms field of mechanical stress. The expression of increment of pressure $p^{\prime}$ can be shown by means of equation [7]:

$$
p^{\prime}=p-p_{0}=C_{0}^{2} \rho^{\prime}+C_{0}^{2} \rho_{0} \beta T^{\prime} .
$$

Here, $\rho_{0}$-equilibrium density of medium, $p^{\prime}=p-p_{0}$-increment of density, $T^{\prime}=T-T_{0}$-increment of temperature, and $\beta=-\frac{1}{\rho}\left(\frac{\partial \rho}{\partial T}\right)_{p}$ - temperature coefficient of cubic expansion of medium, $c_{p}-$ specific heat of medium at constant pressure. In this case, it is possible to consider that $\rho^{\prime}=0$ and, consequently, $p^{\prime}=C_{0}^{2} \rho_{0} \beta T^{\prime}$.

The field of mechanical stress in turn, causes acoustic waves, which propagates from the heated zone. This pressure is propagates equally between a wave escaping from border $z=0$, and wave running in the direction of boundary. Outside of area of heat release, there is only wave propagating from border into the depth of an absorbing medium. Its temporary profile reshapes both direct wave, and wave propagating to boundary and reflected that it.

The profile of an acoustic wave excited in medium is described by the following formula [8,9]:

$$
p^{\prime}=\frac{\alpha C_{0}^{2} \beta \varepsilon_{s}}{2 c_{p}} \times\left\{\begin{array}{l}
\frac{1-N}{1+N} \exp \left[\alpha\left(z-C_{0} t\right)\right], z<C_{0} t, \\
\exp \left[-\alpha\left(z-C_{0} t\right)\right], z>C_{0} t,
\end{array}\right.
$$

where $N=\frac{\rho_{0} C_{0}}{\rho_{t r} C_{t r}}$-ratio of acoustic impedances for absorbing and transparent mediums.

In Figure 2, the profiles of optoacoustical signals at various values of parameter $\alpha C_{0} \tau_{l}$ obtained from Eq. (1) are given. As the 


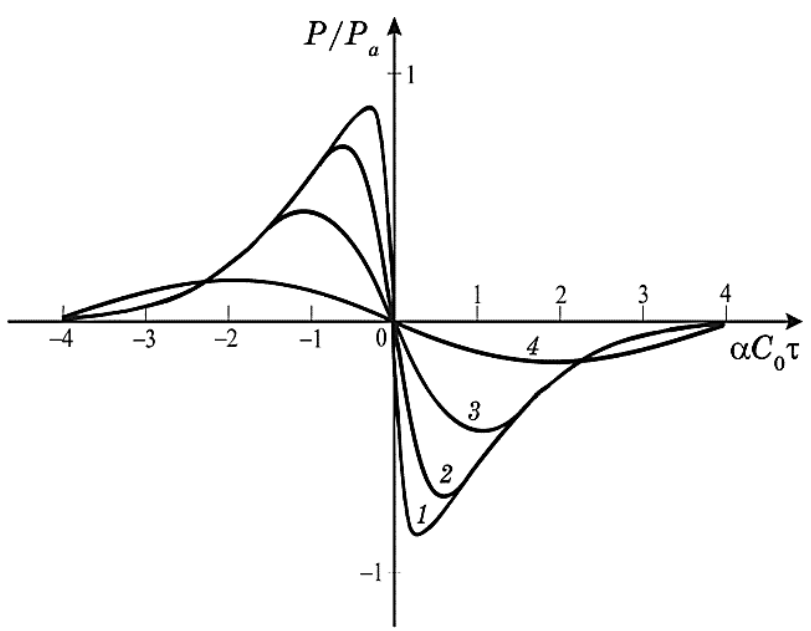

Fig. 2. Profiles of optoacoustical pulses for free boundary at various values of parameter $\alpha C_{0} \tau_{l}$ equal 0.1 (1), $0.3(2), 0.7$ (3), and 1.5 (4).

leading edge of a pulse $\left(\tau=t-z / C_{0}<0\right)$ is reshaped by a direct wave propagating at once from boundary, its profile repeats spacing of potential sources and, for a uniform absorbing medium (with $\alpha=$ const $)$, has the universal exponential form $p^{\prime}(\tau<0) \sim \exp \left(\alpha C_{0} \tau\right)$ . The wave reflected from boundary $z=0$ also has the exponential form, $p^{\prime}(\tau<0) \sim \exp \left(\alpha C_{0} \tau\right)$, and its relative value is determined by a reflection coefficient of acoustic wave.

Under the form of an acoustic signal measured in depth $z$, it is easily possible to determine a propagation time $\tau$ of acoustic wave from a surface up to the given point of medium. Therefore, knowing a bed depth $z$, it is easy to determine a sound velocity in medium as $v=z / \tau$.

Considering that for homogeneous liquid, the theoretically counted form of thermoacoustical pulse of pressure has a simple form $p^{\prime} \sim \exp (-\alpha z)$ presented the dependence of a pressure at the front of acoustic pulse as a function of time in a semi-logarithmic scale, and, on a slope of a straight line, the absorption coefficient of light can be determined.

\section{EXPERIMENTAL ARRANGEMENTS}

Our experimental arrangement is shown in Fig. 3. A periodicalpulse laser operating on a wavelength of $1.06 \mu \mathrm{m}$ is used. Duration and the pulse energy are $\sim 20 \mathrm{~ns}$ and $\sim 5 \mathrm{~mJ}$, accordingly. The part of radiation was routed on a photodetector 3 , which one served for start of a storage-type oscilloscope 6 such as C9-8. 
Other part of radiation was directed vertically onto the liquid, which is contained in cuvette 5 .

The special cuvette is designed to study the temperature dependence of physical parameters of liquids and is shown schematically in Fig. 4.

The cuvette is made of brass. On an outside surface, collars 1 for affixing the jacket for thermostatic control are present. Spacing intervals between the outside and internal surfaces of the cuvette thermostating of the jacket of $15 \mathrm{~mm}$ are equal that provides fast equalization of temperature. The detection of acoustic signals is carried out in real time with a fast piezoelectric detector which is mounted at the bottom of the cuvette indirect contact with the liquid. The resonance frequency of an acoustic unit makes $\sim 39 \mathrm{MHz}$. For measurement of a sound velocity in transparent liquid, where the laser radiation practically is not absorbed and generating acoustic waves in medium do occur, on a surface of liquids, the thin layer of aqueous solution of chloride cuprum is placed. This layer, the depth of which is no more than $\sim 1.5 \mathrm{~mm}$, is in a good acoustic contact to investigated medium 5 and plays a role of the acoustic gen-

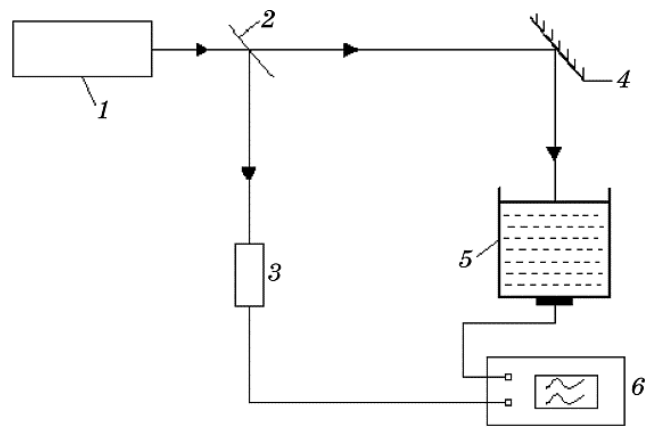

Fig. 3.

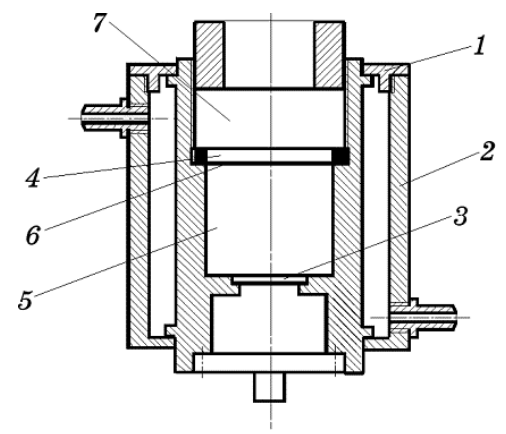

Fig. 4. 
erator. They are partitioned by a thin teflon film 6 . From above of bed of mortar of chloride cuprum, the glass lamina is put and is transparent for a laser radiation. The measurements have shown that the absorption coefficient of a laser radiation in solution $\mathrm{CuCl}_{2}$ makes $\sim 50 \mathrm{~cm}^{-1}$. The laser radiation is practically completely absorbed in solution of chloride cuprum and produces acoustic waves, which propagate in investigated medium.

\section{EXPERIMENTAL}

For check of a measuring system and experimental technique, first of all, a sound velocity in water was measured and, at a room temperature, it is obtained $\sim 1450 \mathrm{~m} / \mathrm{s}$ that, within the limits of accuracy of measurement, is well agreed with the known literary data [10].

The investigation was carried out in oil and in different petroleum from various fields of Azerbaijan. Figures 5, $a, b$ show typical
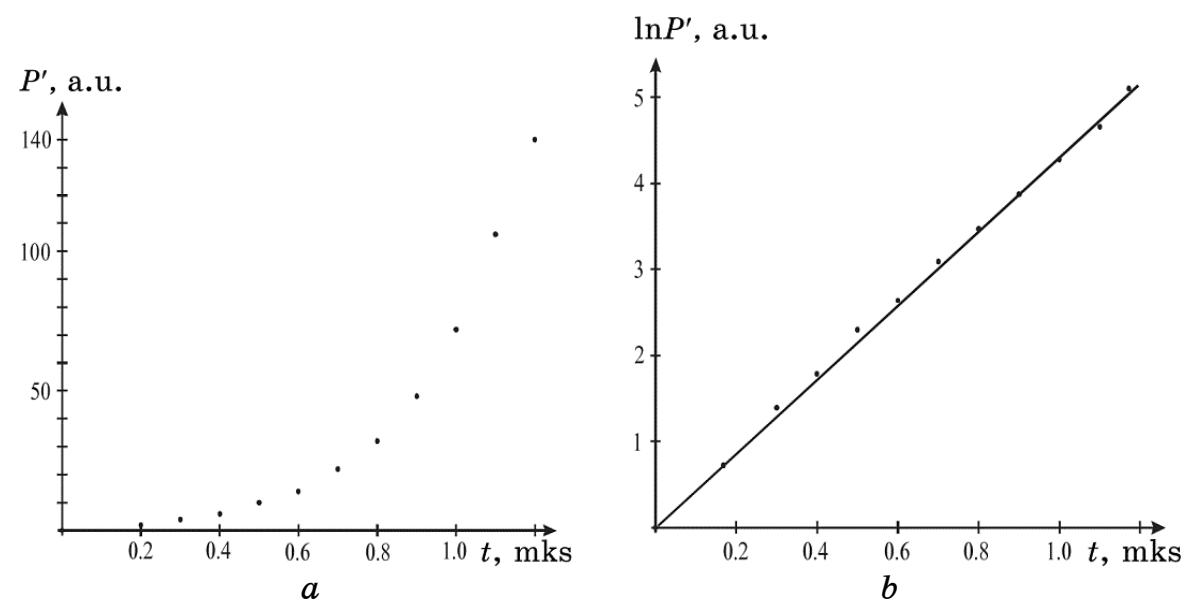

Fig. 5.

TABLE.

\begin{tabular}{c|c|c|c}
\hline No. of a sample & $C_{0}, 10^{3} \mathrm{~m} / \mathrm{s}$ & $\alpha, \mathrm{cm}^{-1}$ & $\begin{array}{c}\text { Fields } \\
\text { of oil extraction }\end{array}$ \\
\hline 1 & 1.46 & 1.3 & Umbaku \\
2 & 1.55 & 2.8 & Absheron \\
3 & 1.45 & 24.8 & Salyan \\
4 & 1.47 & 25.2 & Shirvan \\
5 & 1.6 & 39.3 & Kura \\
\hline
\end{tabular}


data. The profile of acoustic signal (5a) and pressure as a function of time in a semi-logarithmic scale are presented. As expected, the relation has a linear nature. For oil with a large absorption coefficient, the fronts of acoustic signals are more abrupt, and the slope in a semi-logarithmic scale has accordingly the greater slope.

In Table, the obtained data on the indicated technique of a sound velocity, $C_{0}$, and absorption coefficient of light, $\alpha$, in oil from different fields of Azerbaijan are presented. The measurement accuracy of a sound velocity does not exceed $\sim 5 \%$ and was basically determined by accuracy of determination of depth of an investigated layer. The accuracy of determination of a light-absorption coefficient was not worse than $\sim 10 \%$.

With the indicated technique, an absorption coefficient of a laser radiation for different fraction of oils was also measured. As known, these fractions of oils were obtained in following temperature bands: mild gasoline at $62-85^{\circ} \mathrm{C}$, heart cut distillate oil at $85-$ $180^{\circ} \mathrm{C}$, kerosene at $180-240^{\circ} \mathrm{C}$, diesel fuel at $240-350^{\circ} \mathrm{C}$, and boiler oil above $350^{\circ} \mathrm{C}[11]$.

The carried out measurements have shown that optical absorptions of radiation with wavelength of $1.06 \mu \mathrm{m}$ in fractions obtained up to $350^{\circ} \mathrm{C}$ is practically absent.

For oil from fields Oil Rocks, $\alpha \sim 2.7 \mathrm{~cm}^{-1}$ is obtained. The absorption coefficient of boiler oil obtained from this oil makes $\sim 4$ $\mathrm{cm}^{-1}$ and, for a resin, $\alpha \sim 14 \mathrm{~cm}^{-1}$. Thus, accountable for absorptions of radiation with a given wavelength, there are tarry materials. Comparing the absorption coefficients of oil and resin, we obtain the gummosity of given oil as $\sim 20 \%$. There is a good agreement between this value and well-known data obtained by other methods [11]. In these conventional methods, the contents of tarry materials implement allocation them from crude oil. After that, from a ratio of weight of tarry materials to weight of taken crude oil, the content of this fraction in oil is determined [11]. This way of determination of gummosity of oil is labour-consuming and is not operative.

The temperature coefficient of a sound velocity of different oils varies within the limits $2-6 \mathrm{~m} /(\mathrm{s} \cdot \mathrm{K})$.

Investigations of temperature dependences have shown that, in an investigated temperature interval, the absorption coefficient of radiation does not practically varied, while the sound velocity in all oils descends monotonically and rather essentially with increase of temperature (Fig. 6).

\section{CONCLUSION}

Thus, offered and realized experimentally method permitting to de- 


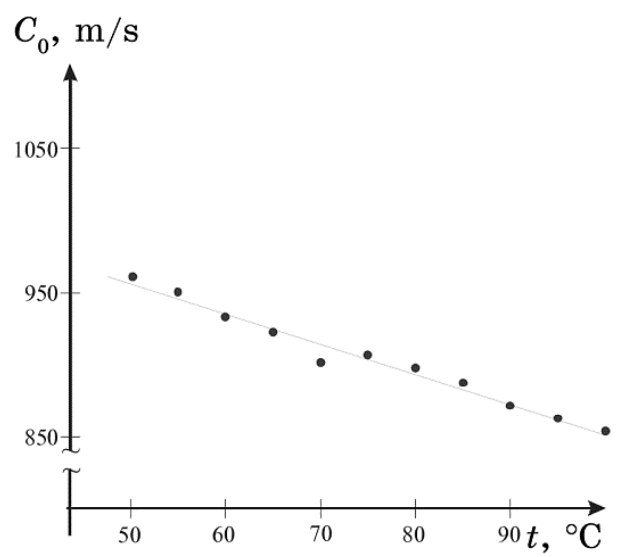

Fig. 6.

termine simultaneously both a light-absorption coefficient and a sound velocity in liquids. This method means measurements of these values for different oils, and the temperature coefficient of sound velocity and gummosity are determined.

\section{REFERENCES}

1. M. W. Sigrist, J. Appl. Phys., 60, No. 7: 109 (1986).

2. A. A. Karabutov and N. B. Podimova, Technical Acoustics, No. 15: 2 (2010) (in Russian).

3. Z. Otremba and H. Toczek, Journal of KONES Power Train and Transport, 18, No. 4: 326 (2011).

4. A. X. Mirzajanzadeh, Paradoxes of Oil Physics (Baku: Azerbaijan State Publishing House: 1981) (in Russian).

5. $\quad$ S. J. Ball and J. P. M. Trusler, Int. J. Thermophys., 22: 427 (2001).

6. V. F. Nozdrev and N. F. Fedorishenko, Molecular Acoustics (Moscow: Vysshaya Shkola: 1974) (in Russian).

7. L. D. Landau and E. M. Lifshitz, Hydrodynamics (Moscow: Nauka: 1986) (in Russian).

8. A. A. Karabutov (Jr.), A. A. Karabutov, and O. A. Sapozhnikov, Physics of Wave Phenomena, 18, No. 4:297 (2010).

9. V. E. Gusev and A. A. Karabutov, Laser Opto-Acoustics (Moscow: Nauka: 1991) (in Russian).

10. J. D. Cutnell and K. W. Johnson, Physics (The Physics Factbook) (New York: Wiley, 1997), p. 468.

11. L. Diyarov, I. Y. Batueva, A. N. Sadikov, and N. L. Solodova, Chemistry of Oil (Leningrad: Khimiya: 1990) (in Russian). 